\title{
BMJ Open Survey on available treatment for acute kidney injury in the Southern African Development Community and Nigeria: are we ready for zero deaths by 2025 in sub-Saharan Africa?
}

\author{
Erika Jones, ${ }^{\oplus 1}$ Brian L Rayner, ${ }^{1,2}$ Emmanuel E Effa, ${ }^{3}$ Ikechi G Okpechi, ${ }^{1,2}$ \\ Michael Schmitz, ${ }^{4,5}$ Peter J Heering ${ }^{4,5}$
}

To cite: Jones E, Rayner BL, Effa EE, et al. Survey on available treatment for acute kidney injury in the Southern African Development Community and Nigeria: are we ready for zero deaths by 2025 in sub-Saharan Africa? BMJ Open 2019;9:e029001. doi:10.1136/ bmjopen-2019-029001

- Prepublication history and additional material for this paper are available online. To view these files, please visit the journal online (http://dx.doi. org/10.1136/bmjopen-2019029001).

Received 10 January 2019 Revised 27 June 2019 Accepted 25 July 2019

Check for updates

(C) Author(s) (or their employer(s)) 2019. Re-use permitted under CC BY-NC. No commercial re-use. See rights and permissions. Published by BMJ.

For numbered affiliations see end of article.

Correspondence to Professor Brian L Rayner; brian.rayner@uct.ac.za

\section{ABSTRACT}

Objectives The International Society of Nephrology (ISN) has called for zero deaths by 2025. This survey aimed to determine the preparedness of Southern African Development Community (SADC) countries and Nigeria to heed this call.

Setting A questionnaire was emailed to facilities, where renal replacement therapy is available; to determine type of services available; quality of care and identify clinicians involved.

Participants Clinicians and administrators involved in the care of patients with acute kidney injury (AKI) completed the questionnaire.

Results Completed questionnaires were received from 12 of the 15 SADC countries and Nigeria, covering 48 service providers. The government provided partial funding for dialysis in $41.7 \%$ of services. There was no funding for acute dialysis in two countries. Interdisciplinary teams in $72.9 \%$ of hospitals covered the intensive care units (ICUs), which included at least one nephrologist in $75 \%$. Only $77 \%$ were able to provide dialysis in ICU. Intermittent haemodialysis was the most common modality available (91.7\% of facilities), sustained low-efficiency dialysis in $50 \%$, continuous therapies in $35 \%$ and peritoneal dialysis in $33.3 \%$. Almost half (47.9\%) of the sites were limited to one mode of dialysis and unable to care for severely ill patients. The clinical status was used to initiate and monitor dialysis, with very few sites having clear written standard operating procedures.

Conclusion In the 16 countries surveyed, the majority had limited ability to provide comprehensive dialysis programmes for patients with AKI due to lack of facilities and government funding. Additionally, nephrologists are scarce; modes of dialysis are limited; as is the care for severely ill patients and lack of standard operating procedures. Resources, training and funding need to be made available to create universal coverage of dialysis for AKI. The ISN goal of providing renal replacement therapy to all by 2025 is unlikely to be achieved in SADC and Nigeria.

\section{INTRODUCTION}

Worldwide, it is estimated that acute kidney injury (AKI) causes 1.7 million deaths per
Strengths and limitations of this study

- New information on services for acute kidney injury in Africa.

- There is limited scope for improvement on services.

- No comprehensive epidemiological data.

- Limited site-specific data gathered.

- Incomplete data were provided and questionnaires were not returned by $38 \%$ of sites.

annum, ${ }^{1}$ but in low/middle-income countries (LMICs) in Africa, Asia and Latin America, lack of access to dialysis is causing an excess of preventable deaths due to the effects of kidney failure rather than the underlying precipitating cause. For this reason, the International Society of Nephrology (ISN) has set a goal to have zero preventable deaths from AKI by ${ }^{1} 2025$ especially in Africa, Asia and Latin America. $^{2}$

In order to eliminate death from AKI, strategies need to be developed to detect, diagnose, monitor and manage AKI especially in LMIC. There is little information on the burden of AKI in Africa and availability of facilities for acute dialysis. ${ }^{3}$ A systematic review ${ }^{4}$ demonstrated the inadequate care available for the management of AKI in sub-Saharan Africa (SSA). The provision of care for patients with AKI was limited by delays in hospitalisation; lack of the use of standardised definitions for AKI and poor access to dialysis $(33 \%$ for adults and $64 \%$ for children). The poor access was the result of an inability to pay for dialysis or the diagnosis of AKI was not made because of limited resources. Mortality in patients in whom dialysis was indicated but not received was $74 \%$ in children and $86 \%$ in adults. This excess in mortality was predicted 
by an inability to pay for dialysis and patients presenting late with severe uraemia and oliguria.

Initial AKI requires treatment of the underlying cause, optimisation of fluid balance, withdrawal of nephrotoxic drugs or toxins and monitoring of kidney function and urine output with minimal extra cost. However, if kidney failure does not respond to initial management, life-threatening complications, like fluid overload, hyperkalaemia, acidosis and uraemia, may develop necessitating the initiation of dialysis that is expensive and requires specialised care. Overburdened healthcare systems of the LMICs in Africa often do not have the facilities to provide adequate care for AKI due to cost constraints, shortage of equipment and facilities, and lack of trained staff. This has resulted in a discrepancy between those that need dialysis for AKI and those that receive it. ${ }^{5}$

A multinational survey assessing global kidney healthcare highlights the disadvantages experienced in Africa. ${ }^{6}$ In the 32 African countries that responded to the survey, only 10 had full funding by government healthcare for haemodialysis (HD) and 3 out of 11 for peritoneal dialysis (PD) for AKI. Provision for medications was even less with only 1 out of 32 countries providing full access.

A single-centre study from South Africa found that AKI was present in $3.4 \%$ of hospital admissions with a high mortality. ${ }^{7}$ This study was performed in a tertiary centre in an upper-middle-income country showed that sepsis was the most common precipitating cause for AKI. The patient profile was significantly different from developed countries with a median age of 44 years compared with 76.2 years in a study from the $\mathrm{UK}^{8}$ and 71.5 years in Germany. ${ }^{9}$ Furthermore, there was a difference in the patient profile: the presence of underlying renal disease was $10.1 \%$ vs $36.2 \%$, and the 30 and 90 days mortality from these studies were $30.9 \%$ and $37.3 \%$, respectively. In contrast, a single-centre study from the Democratic republic of Congo (DRC) ${ }^{10}$ found that $58 \%$ of patients admitted to the intensive care unit (ICU) with AKI died and only $6.5 \%$ actually received dialysis. Because of the discrepancies in care between countries in Africa, it is important to document the situation to assist in determining the needs of countries to assist with 2025 goals of the ISN.

It is against this background that it was decided to conduct a regional survey to delineate the availability, resources and funding for the care of patients with AKI in the Southern African Development Community (SADC) and other African countries.

\section{METHODS}

The study was modelled on a similar survey performed in Germany. ${ }^{11}$ It was conducted in SADC countries (Angola, Botswana, DRC, Lesotho, Malawi, Madagascar, Mauritius, Mozambique, Namibia, Seychelles, South Africa, Swaziland, Tanzania, Zambia and Zimbabwe). The decision not to survey the entire SSA was that resources for the survey were limited and investigators had relatively good contacts in the SADC region and Nigeria. There was a concern that incomplete information would be obtained from other countries in SSA and skew the data. Similarly, in South Africa, data were restricted to the Western Cape as dialysis for AKI is widely available in South Africa and the investigators had greater knowledge of nephrologists and dialysis centres in the region. Data were collected by means of a questionnaire, (online supplementary appendix 1), which was developed by a steering committee of the German Association of Intensive Care Medicine. The questionnaire has been applied and published and to compare these results, the main questions were translated.

The questionnaire was sent to the clinicians involved in the care of patients with AKI. They were requested to complete the questionnaire and return via email or fax to the authors. The clinicians were informed that the questionnaire would be collated into a database and the results would be published. At all stages, this was voluntary. The questionnaire was composed of 20 questions on the facilities of the hospital and ICUs, the qualifications of the clinicians providing AKI care, prevalence of AKI, treatment modalities and delivery of care. Data collection started in April 2016 and concluded in September 2017.

A database of nephrologists and intensivists and hospitals was created from the ISN, African Society of Nephrology, European Dialysis and Transplantation Association membership lists, and personal contacts of the investigators. The database included nephrologists from the 15 SADC countries and Nigeria. In order to minimise missing countries and services, the respondents were asked to give details of other nephrologists and hospitals that provide dialysis for AKI. The questionnaire was emailed to all contacts.

Where there was no response to emails, attempts were made to contact the hospitals or clinicians by telephone. In some instances, the questionnaires were handed directly to doctors at international meetings. Small district hospitals that responded to the questionnaire but did not provide dialysis were excluded from analysis.

\section{Patient and public involvement}

There was no patient or public involvement.

\section{RESULTS}

A total of 90 questionnaires were sent to units in the SADC. Completed questionnaires were received from a total of 12 countries: 11 out of 15 SADC countries and Nigeria. No results were returned from Angola, Mauritius, Madagascar or the Seychelles. The 12 countries involved had 78 sites that provided acute dialysis; questionnaires were returned from 48 (62\%) services (some service providers consult to multiple centres). A further three questionnaires were returned from basic district hospitals in SADC countries that do not provide any form of renal replacement therapy (RRT) and were excluded from analysis. Figure 1 shows the distribution of countries 


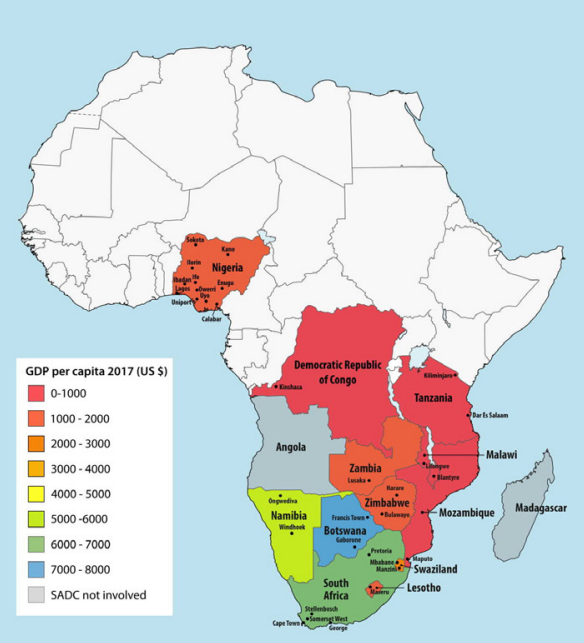

Figure 1 Map of Africa demonstrating the countries and cities involved in the survey. GDP, gross domestic product; SADC, Southern African Development Community.

involved in the survey and the cities from where the questionnaires were returned.

The questionnaire was completed by a specialist involved in $41(85.4 \%)$ cases. In others it was completed by a medical officer (five questionnaires-10.4\%), a nurse and an administrator in one case each. The majority of the hospitals involved in the questionnaire were either tertiary $(23 / 47.9 \%)$ or university hospitals $(20 / 41.7 \%)$. Only three were hospitals of basic or standard care. Two did not specify. University hospitals provide full services and are attached to teaching units. Tertiary hospitals cover all services but are not attached to a teaching hospital and include privately funded institutions. Both university and tertiary hospitals are typically located in major cities.

Only in South Africa was acute dialysis funded completely by the government. In the remaining countries, there was partial funding, except for Nigeria and Zimbabwe where patients had to fund their own dialysis, either through private insurance or self-funding. Indicators of wealth ${ }^{12}$ are provided in table 1 with the sites available in each country and the number that responded to the questionnaire.

Another important limitation to accessing acute dialysis was proximity to emergency medical services. A large proportion of the population in these countries live further than 2 hours away from emergency medical services, ${ }^{13}$ table 1 .

The majority of hospitals (72.9\%) had multidisciplinary ICUs with interdisciplinary teams providing the care for the patients. There is a nephrologist involved in the care and dialysis prescription of the patients with AKI in 36 $(75 \%)$ sites. There was a specialist involved in $80 \%$ of sites.

Dialysis in the ICU was available in only $37(77.1 \%)$ hospitals, but in the remaining hospitals, it was performed in dialysis units or wards and sites were unable to support severely ill patients. The maximum number of beds in any one ICU was 15.

Intermittent HD was available for AKI in 44 (91.7\%) sites; prolonged intermittent dialysis or sustained low efficiency dialysis (SLED) in $24(50 \%)$; continuous dialysis in $18(37 \%)$ and PD in $16(33.3 \%)$. In two sites (one each from Nigeria and Tanzania), only PD was available. In all remaining sites that used PD, HD was also available. In $23(47.9 \%)$ sites, all patients were treated with either,

Table 1 Resources in the countries involved in the survey

\begin{tabular}{|c|c|c|c|c|c|c|c|c|}
\hline & $\begin{array}{l}\text { GDP } 2017 \\
\text { (million) }\end{array}$ & $\begin{array}{l}\text { Population } \\
2017 \\
\text { (million) }\end{array}$ & $\begin{array}{l}\text { GDP per } \\
\text { capita } \\
2017 \\
\text { (US\$) }\end{array}$ & $\begin{array}{l}\text { Spending on } \\
\text { healthcare } \\
2014(\%)\end{array}$ & $\begin{array}{l}\text { Percentage } \\
\text { of population } \\
\text { outside } \\
\text { 2-hour travel } \\
\text { time }\end{array}$ & $\begin{array}{l}\text { Sites } \\
\text { providing } \\
\text { acute } \\
\text { dialysis }\end{array}$ & $\begin{array}{l}\text { No of } \\
\text { sites } \\
\text { involved } \\
\text { in the } \\
\text { survey }\end{array}$ & $\begin{array}{l}\text { Nephrologists } \\
\text { in } 2017\end{array}$ \\
\hline Nigeria & 375770.71 & 190.88631 & 1968.6 & 3.7 & 7.7 & 20 & 13 & 180 \\
\hline SA -WC & 349419.34 & 56.71716 & 6160.7 & 8.8 & $5.2 \#$ & 25 & 16 & 25 \\
\hline Botswana & 17406.53 & 2.29166 & 7595.6 & 5.4 & 23.3 & 3 & 3 & 4 \\
\hline Malawi & 6303.28 & 18.62210 & 338.5 & 11.4 & 7.2 & 4 & 2 & 0 \\
\hline Mozambique & 12333.86 & 29.66883 & 415.7 & 7.0 & 49.9 & 1 & 1 & 1 \\
\hline Namibia & 13244.60 & 2.53379 & 5227.2 & 8.9 & 23.2 & 3 & 2 & 2 \\
\hline Swaziland* & Not reported & Not reported & 2775.2 & 9.3 & 6.1 & 3 & 3 & 1 \\
\hline Zimbabwe & 17845.82 & 16.52990 & 1079.6 & 6.4 & 20.7 & 3 & 1 & 4 \\
\hline DRC & 37241.30 & 81.33999 & 457.8 & 4.3 & 46.3 & 5 & 2 & 2 \\
\hline
\end{tabular}

\# Data for entire country[13]

*Swaziland report for 2016.

DRC, Democratic Republic of Congo; GDP, gross domestic product. 

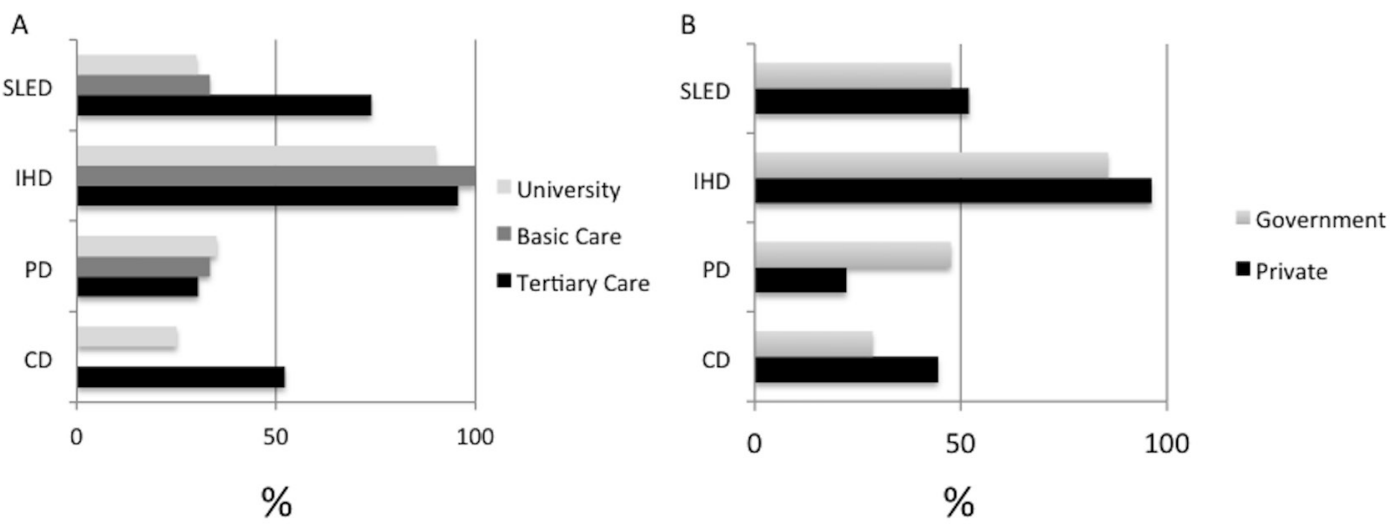

Figure 2 Dialysis availability (A) by type of hospital; (B) by funding source. CD, continuous dialysis; IHD, intermittent haemodialysis; PD, peritoneal dialysis; SLED, sustained low-efficiency dialysis.

regardless of degree of illness because only intermittent HD or PD was available.

The patient's clinical status was used for initiating and monitoring of dialysis in $37(77.1 \%)$ sites; in $11(22.9 \%)$ urea and electrolytes and in $5(10.4 \%)$ the $\mathrm{Kt} / \mathrm{V}$. The use of dialysis was available for reasons other than AKI in a few sites: $7(14.6 \%)$ sites for sepsis; $12(25 \%)$ sites for heart failure and $23(47.9 \%)$ sites for toxin removal. Figure 2 demonstrates the difference in available types of dialysis depending on the type of hospital (1) and whether the care for AKI was privately funded or funded by government (2).

The dialysis was performed with bicarbonate as a buffering agent in $22(45.8 \%)$ and lactate in three $(6.3 \%)$ sites. The remaining sites did not specify their buffering agent. Unfractionated heparin was available in $31(64.6 \%)$ sites, low-molecular-weight heparin in $22(45.8 \%)$ sites and citrate in $6(12.5 \%)$. Nine $(18.8 \%)$ sites used no anticoagulation at times. The type of dialysis used for various indications is shown in figure 3. There was no statistical difference in any of these data.

In over $80 \%$ of hospitals, the clinical situation was used to initiate and continue or stop dialysis. Less than $20 \%$ used the AKI Network (AKIN) or risk, injury, failure, loss, end-stage renal disease criteria to initiate dialysis or for

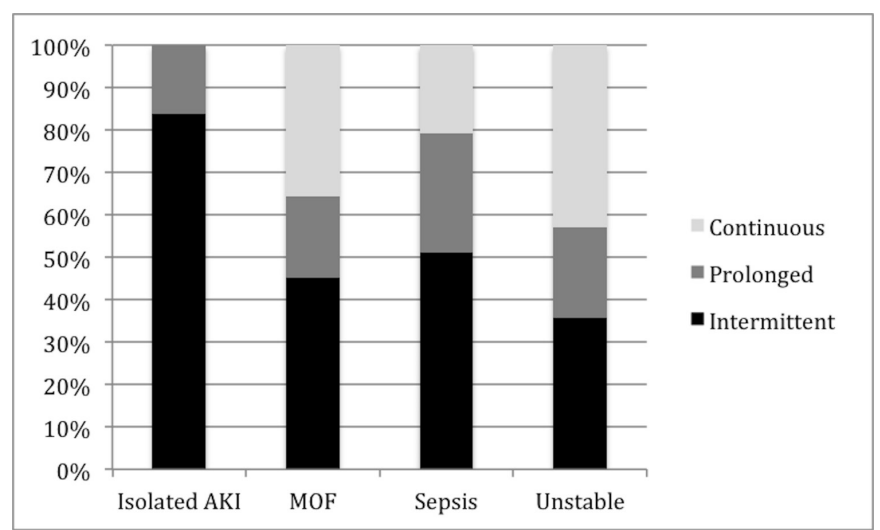

Figure 3 Type of dialysis for indication. AKI, acute kidney injury; MOF, multiorgan failure. the length of dialysis. Written standard operating procedures or guidelines indicating when to initiate RRT and how to monitor or care for patients on dialysis were only available in $37.5 \%$ of sites. Twenty-one $(39.6 \%)$ and 25 (46.3\%) services reported that the economic situation was considered important in initiating and continuing dialysis, respectively. Furthermore, three services (two in Nigeria and one in Zimbabwe) stated that the frequency of dialysis was impacted by the patient's ability to fund the dialysis.

\section{DISCUSSION}

This survey from SADC and Nigeria assessed the services available to provide RRT to patients with AKI. In the 16 countries invited, only 12 responded and the majority had very limited ability to provide dialysis for patients with AKI. Most countries had one or two centres in major cities, leaving rural areas uncovered. In most of the countries, the patients and families partially or fully fund dialysis. The government covered the full cost of acute dialysis in South Africa only.

The observation that dialysis is generally funded by the individual rather than the government is in keeping with previous reports. ${ }^{14}$ Around $40 \%$ of the services' ability to provide dialysis was impacted by the economic situation. This was seen for initiation, continuing and amount of dialysis provided. Available support for kidney disease in Africa was reviewed and documented the poor use of RRT in Africa. ${ }^{15}$ AKI frequently complicates patients who are critically ill and dramatically increases mortality. ${ }^{10}$ Poor or limited resource allocation to healthcare is clear and correlates with the gross domestic product per capita of the population. Accessibility to healthcare services is another indicator of the healthcare services. When reviewing the available information in demographic and healthcare surveys, ${ }^{16}$ there are no data available on provision of care for AKI in the countries involved in this survey. Ouma $e t$ $a l^{13}$ describe time to available healthcare services. Large proportions of the people of many of these countries live further than 2 hours away from hospitals. Access to 
healthcare for emergency maternity services has been described and has been found to be inadequate in many of the countries surveyed. ${ }^{17}$ This is likely to be even more marked for access to RRT. The information available from this database does not include sufficient data on level of hospitals in each country to determine the proportion of secondary or tertiary hospitals providing acute dialysis or on availability of RRT. However, Mehta $e t a l^{18}$ found that $15 \%$ of HMIC and 20\% of LMICs centres participating in their survey were located in cities with $<500000$ people. This dearth of data needs to be addressed for Africa and this survey attempts to do this.

The survey demonstrates the scarcity of nephrologists available to support renal replacement programmes. In many situations, there was one nephrologist available to assist in the care of patients with all renal disorders, sometimes in the entire country and sometimes for large geographical areas. Consequences of limited nephrologist cover have led to discrepancies in provision of care ${ }^{19}$ There were a number of nephrologists who covered multiple sites, sometimes in different cities, in order to provide subspecialty services to more areas. It is clear that nephrology training needs to be reviewed and improved, a proposal that has been outlined by Okel $e t a l^{20} \mathrm{~A}$ task shifting policy involving the training of nurse practitioners in the provision of PD may be the solution to improve geographical coverage for AKI care.

The services available to support patients with AKI are also limited in other ways. Services are generally confined to the major cities and only $77.1 \%$ of sites that responded were able to provide dialysis in the ICU. Furthermore, written standard operating procedures or guidelines indicating when to initiate RRT and how to monitor or care for patients on dialysis were only available in $37.5 \%$ of sites. The limitation of the services leads to the late presentation and delays in initiation of RRT, ${ }^{4}$ which is associated with an increase in mortality.

Data from Germany show that continuous dialysis is a tool that is frequently used, and exclusively used in University hospitals in the ICU. ${ }^{11}$ The data from SADC and Nigeria show that the availability of continuous dialysis (37\% of sites) or even SLED (in 50\% of sites) is extremely limited. The benefit of continuous dialysis for AKI has previously been demonstrated ${ }^{21}$ suggesting that RRT for AKI is inadequate in the countries involved in this survey. These factors limit the ability to provide dialysis to all patients who present with AKI. An alternative to $\mathrm{HD}$ is the use of PD, which will allow for the support of severely ill and haemodynamically unstable patients. Acute PD is available in 16 sites that were involved in this survey and in two of the sites it was the only modality for acute dialysis. It is successful as a means to dialysis patients without the need for ICU care. Furthermore, it could be used in more rural settings, decreasing the need for transporting patients over long distances.

At first glance PD may be the solution for providing global dialysis cover in Africa, but for success, acute PD requires a dedicated and enthusiastic team. The advantage is that there is no requirement for dialysis machines. However, adequate staff training will be required and a means to create and supply affordable solutions needs to be addressed. Further benefits of PD over HD are that it can be provided in patients who are not haemodynamically stable and laboratory monitoring may not be as necessary. The limitations are that it may not be available in certain instances: severe fluid overload, pregnancy and previous abdominal surgery to name a few. Feasibility and outcome studies will be required to determine if this truly is an ideal alternative option.

Another important limitation is the cost of PD. In South Africa, in the public sector, the cost of PD bags for 6 exchanges is US\$27 per day. (BR, personal communication) One HD or SLED session that includes the dialyser, connexions and intravenous fluids is US $\$ 27$ and US $\$ 35$, respectively. The daily cost for CVVHD in contrast is US $\$ 80$. These estimates do not include staff (required for 24 hours), water and catheter costs. HD and SLED can often be performed on alternate days so disposable costs are actually lower for HD and SLED.

In Nigeria, the cost of six PD exchanges is US\$60, and a single session of HD US $\$ 100$. (EE, personal communication) The lower costs of disposables in SA compared with Nigeria, is probably due to local manufacture, less use of imported goods, and bulk buying in the public sector by use of a tender system in South Africa. It is likely a similar situation to Nigeria exists in other countries in the SADC region. There is some hope that mixing PD solutions from standard intravenous solutions can reduce these costs. Some centres have used mixtures of Ringers lactate combined with 50\% dextrose as PD fluid. Both these solutions are easily available in most centres, making this an accessible solution.

While the availability of laboratory support was not part of the current survey, it has previously been reported that $18 \%$ of African countries have creatinine available for monitoring chronic dialysis. ${ }^{6}$ Managing acute HD without laboratory support limits the ability to use AKIN for the diagnosis of AKI. The limitation of services leads to the late presentation and delays in initiation of RRT, ${ }^{4}$ which is associated with an increase in mortality.

Anticoagulation is generally required during dialysis, particularly with continuous dialysis. In most situations, heparin or low-molecular-weight heparin is used. In three countries, citrate was available for anticoagulation as an alternative to heparin. This is in contrast to data from Germany where citrate is used in 50\%-90\% of hospitals. ${ }^{11}$ Citrate may not be a superior mode of anticoagulation but is an alternative when heparin is contra indicted due to bleeding. ${ }^{22}$ The lack of availability of citrate in Africa provides further challenges in managing critically ill patients with AKI. However, with the limited availability of laboratory monitoring noted in Africa, citrate use remains limited.

The ISN goal of providing RRT to all by $2025^{1}$ is highly unlikely to be attained in SSA. The snapshot of data available provided by the ISN demonstrates the discrepancies 
in healthcare provision, based on gross national income. This pilot study performed by the 0 by 25 team highlights the variation in causes and presentations in the different regions. Our survey further demonstrates severe shortcomings in the provision of treatment for AKI and even if a major investment in infrastructure and training was to start, it is very unlikely that the goal will be achieved. Although the ISN should be congratulated for training nephrologists in Africa, at the present rate, this is unlikely to redress the severe shortage of skills. The economic inequities in low-income and low-to-middle income countries do not appear to have been completely recognised when creating the 0 by 25 goal.

The Kidney Disease Improving Global Outcomes (KDIGO) controversies conference ${ }^{23}$ has identified issues pertaining to the delivery of RRT for AKI in LMICs. The majority of the countries in this survey fall into the LMIC bracket (excluding South Africa). The KDIGO controversies meeting highlights the importance of engaging at all levels of the healthcare structure; including with policy-makers, epidemiologists and all medical services ranging from the primary healthcare systems to the tertiary systems.

However, it is essential that a roadmap for care of patients with AKI needs to be developed for SSA. This should provide practical guidance for the care of patients with AKI, and focus initially in identifying patients with reversible conditions with a good prognosis to optimise use of scarce resources. In addition, this document should form a basis for lobbying African governments and the African Union to provide a basic standard of care for AKI, and promote training and education to address the severe skills shortage.

Policy-makers were not included in the survey. Replies from health department officials in Africa are notoriously difficult, as demonstrated by $10 \%$ answering in the Global Kidney Health Survey. ${ }^{6}$ This survey was unable to determine the attitude of policy-makers towards the provision of dialysis for AKI. Neither does the survey determine the economic requirements to provide dialysis across the region. This was not the aim of the survey but rather the aim was to determine what is available and what coverage is supplied for AKI in SADC and Nigeria. A further shortcoming of the survey was the inability to determine epidemiological data for AKI in these countries. A much more in-depth survey will be required to gather these data. It is further noted that the data are incomplete, particularly in the lowest income countries. In the DRC, Malawi and Namibia the sites that did not answer were privately funded medical services. In Tanzania, Zambia and Zimbabwe, the non-responding services were from both the private and the government sector. In 7/14 non-responding sites from these countries, it is known that a nephrologist was available to assist in the care of patients with AKI. Incomplete data complicate and bias interpretation of the results. Unknown details from the sites that did not return the questionnaires cannot be taken into account.

\section{CONCLUSION}

In order to provide universal coverage of RRT for AKI, there needs to be a significant improvement in funding available to healthcare in Africa. Furthermore, guidelines to improve differentiation of patients have to be developed, to identify those with good prognosis. Funding needs to improve available equipment and services especially in areas outside of major cities. There needs to be a concerted effort in training nephrologists and dialysis personnel to develop the skills required for RRT and a mind shift towards the use of PD for AKI.

\section{Author affiliations}

${ }^{1}$ Kidney and Hypertension Research Unit, University of Cape Town, Cape Town, South Africa

${ }^{2}$ Division of Nephrology and Hypertension, University of Cape Town, Cape Town, South Africa

${ }^{3}$ Department of Internal Medicine, University of Calabar, Calabar, Nigeria ${ }^{4}$ Nephrology, Heinrich Heine University of Düsseldorf, Solingen, Germany

${ }^{5}$ Solingen General Hospital, Solingen, Germany

Contributors EJ, BLR and PJH were involved in the design, research, analysis and writing of the paper. EEE and IGO were involved in the research and writing of the paper. MS was involved in the design and writing of the paper.

Funding This study was funded by support of the Jackstaedt Foundation, Wuppertal, Germany.

Map disclaimer The depiction of boundaries on the map(s) in this article do not imply the expression of any opinion whatsoever on the part of BMJ (or any member of its group) concerning the legal status of any country, territory, jurisdiction or area or of its authorities. The map(s) are provided without any warranty of any kind, either express or implied.

\section{Competing interests None declared.}

Patient consent for publication Not required.

Ethics approval This study received approval from the University of Cape Town Research Ethics Committee; HREC REF: 155/2016.

Provenance and peer review Not commissioned; externally peer reviewed.

Data availability statement All data relevant to the study are included in the article or uploaded as online supplementary information.

Open access This is an open access article distributed in accordance with the Creative Commons Attribution Non Commercial (CC BY-NC 4.0) license, which permits others to distribute, remix, adapt, build upon this work non-commercially, and license their derivative works on different terms, provided the original work is properly cited, appropriate credit is given, any changes made indicated, and the use is non-commercial. See: http://creativecommons.org/licenses/by-nc/4.0/.

\section{REFERENCES}

1. Mehta RL, Cerdá J, Burdmann EA, et al. International Society of nephrology's 0by25 initiative for acute kidney injury (zero preventable deaths by 2025): a human rights case for nephrology. Lancet 2015;385:2616-43.

2. ISN. Available: https://www.theisn.org/all-articles/616-0by25

3. Barsoum RS, Khalil SS, Arogundade FA. Fifty years of dialysis in Africa: challenges and progress. Am J Kidney Dis 2015;65:502-12.

4. Olowu WA, Niang A, Osafo C, et al. Outcomes of acute kidney injury in children and adults in sub-Saharan Africa: a systematic review. Lancet Glob Health 2016;4:e242-50.

5. Abu-Aisha H, Elamin S. Peritoneal dialysis in Africa. Perit Dial Int 2010;30:23-8.

6. Bello AK, Levin A, Tonelli M, et al. Assessment of global kidney health care status. JAMA 2017;317:1864-81.

7. Dlamini TAL, Heering PJ, Chivese T, et al. A prospective study of the demographics, management and outcome of patients with acute kidney injury in Cape town, South Africa. PLoS One 2017;12:e0177460. 
8. Kolhe NV, Muirhead AW, Wilkes SR, et al. The epidemiology of hospitalised acute kidney injury not requiring dialysis in England from 1998 to 2013: retrospective analysis of hospital episode statistics. Int $J$ Clin Pract 2016;70:330-9.

9. Schmitz M, Tillmann F, Paluckaite A, et al. Mortality risk factors in intensive care unit patients with acute kidney injury requiring renal replacement therapy: a retrospective cohort study. Clin Nephrol 2017;88:27-32.

10. Masewu A, Makulo J-R, Lepira F, et al. Acute kidney injury is a powerful independent predictor of mortality in critically ill patients: a multicenter prospective cohort study from Kinshasa, the Democratic Republic of Congo. BMC Nephrol 2016;17:118.

11. Schmitz M, Heering PJ, Hutagalung $R$, et al. Jorres $A$ : [Treatment of acute renal failure in Germany: Analysis of current practice]. Med Klin Intensivmed Notfmed 2015;110:256-63.

12. Bank W. Available: https://data.worldbank.org/indicator/NY.GDP. PCAP.KN

13. Ouma PO, Maina J, Thuranira PN, et al. Access to emergency hospital care provided by the public sector in sub-Saharan Africa in 2015: a geocoded inventory and spatial analysis. Lancet Glob Health 2018;6:e342-50.

14. Abdou N, Antwi S, Koffi LA, et al. Peritoneal dialysis to treat patients with acute kidney Injury-The saving young lives experience in West Africa: proceedings of the saving young lives session at the first International Conference of dialysis in West Africa, Dakar, Senegal, December 2015. Perit Dial Int 2017;37:155-8.
15. Swanepoel CR, Wearne N. Okpechi Ig: nephrology in Africa-not yet uhuru. Nat Rev Nephrol 2013;9:610-22.

16. Demographic Health Surveys. Available: https://dhsprogram.com/

17. Banke-Thomas A, Wright K, Collins L. Assessing geographical distribution and accessibility of emergency obstetric care in subSaharan Africa: a systematic review. J Glob Health 2019;9:010414.

18. Mehta RL, Burdmann EA, Cerdá J, et al. Recognition and management of acute kidney injury in the International Society of nephrology 0by25 global snapshot: a multinational cross-sectional study. Lancet 2016;387:2017-25.

19. Kilonzo KG, Jones ESW, Okpechi IG, et al. Disparities in dialysis allocation: an audit from the new South Africa. PLoS One 2017;12:e0176041.

20. Okel J, Okpechi IG, Qarni B, et al. Nephrology training curriculum and implications for optimal kidney care in the developing world. Clin Nephrol 2016;86:110-3. 2016.

21. Brause M, Grabensee B, Heering P. Strategies for the treatment of acute renal failure in intensive care units: the aspect of dosing. Ren Fail 2004;26:209-13.

22. Hetzel GR, Schmitz M, Wissing $\mathrm{H}$, et al. Regional citrate versus systemic heparin for anticoagulation in critically ill patients on continuous venovenous haemofiltration: a prospective randomized multicentre trial. Nephrol Dial Transplant 2011;26:232-9.

23. Jha V, Arici M, Collins AJ, et al. Understanding kidney care needs and implementation strategies in low- and middle-income countries: conclusions from a "Kidney Disease: Improving Global Outcomes" (KDIGO) Controversies Conference. Kidney Int 2016;90:1164-74. 